\title{
Pulmonary capillary recruitment in exercise and pulmonary hypertension
}

To the Editor:

We read with interest the excellent European Respiratory Society statement on exercise pulmonary hypertension ( $\mathrm{PH}$ ) by Kovacs et al. [1] in the European Respiratory Journal. Fundamentally, exercise $\mathrm{PH}$, especially with precapillary causes such as pulmonary arterial hypertension (PAH), is an inability of the lung circulation to accommodate increased blood flow during exercise. Although the authors mention "distention" of the vasculature, implying stretching of already perfused vessels, the increased pulmonary blood flow is primarily accommodated in the normal lung by recruitment of unused capillaries, allowing the pulmonary artery pressure to change minimally during exercise [2, 3]. Further evidence of this recruitment is found in true vasoresponders during an acute vasodilator challenge for evaluation of idiopathic PAH [4]. By contrast, because it is caused by precapillary vascular obstruction and not vasoconstriction, vasodilator-nonresponsive $\mathrm{PAH}$ accommodates any increased cardiac output via distention and not via recruitment [5]. We have also observed pulmonary capillary recruitment in normal humans during exercise (unpublished data). Recruitment is a normal physiological process, and it is impaired in many types of $\mathrm{PH}$. As we move forward in our understanding of exercise $\mathrm{PH}$ and its physiology, precise definitions and semantics will be critical.

\section{@ERSpublications}

Pulmonary capillary recruitment is important in the pulmonary haemodynamic response to exercise http://ow.ly/tKJm30icJkp

Cite this article as: Langleben D, Orfanos SE. Pulmonary capillary recruitment in exercise and pulmonary hypertension. Eur Respir J 2018; 51: 1702559 [https://doi.org/10.1183/13993003.02559-2017].

David Langleben $^{1}$ and Stylianos E. Orfanos ${ }^{2}$

${ }^{1}$ Center for Pulmonary Vascular Disease, Cardiology Division, Jewish General Hospital and McGill University, Montreal, QC, Canada. ${ }^{2}$ Pulmonary Hypertension Clinic, Attikon Hospital and 2nd Dept of Critical Care, National and Kapodistrian University of Athens, Athens, Greece.

Correspondence: David Langleben, Jewish General Hospital, E-206, 3755 Cote Ste Catherine, Montreal, QC, H3T 1E2, Canada. E-mail: david.langleben@mcgill.ca

Received: Dec 092017 | Accepted: Jan 082018

Conflict of interest: None declared.

\section{References}

1 Kovacs G, Herve P, Barbera JA, et al. An official European Respiratory Society statement: pulmonary haemodynamics during exercise. Eur Respir J 2017; 50: 1700578.

2 Dupuis J, Goresky CA, Ryan JW, et al. Pulmonary angiotensin-converting enzyme substrate hydrolysis during exercise. J Appl Physiol 1992; 72: 1868-1886.

3 Dupuis J, Goresky CA, Rouleau JL, et al. Kinetics of pulmonary uptake of serotonin during exercise in dogs. J Appl Physiol 1996; 80: 30-46.

4 Langleben D, Orfanos SE, Giovinazzo M, et al. Acute vasodilator responsiveness and microvascular recruitment in idiopathic pulmonary arterial hypertension. Ann Intern Med 2015; 162: 154-156.

5 Langleben D, Orfanos S. Vasodilator responsiveness in idiopathic pulmonary arterial hypertension: identifying a distinct phenotype with distinct physiology and distinct prognosis. Pulm Circ 2017; 7: 588-597.

Copyright @ERS 2018

From the authors:

We appreciate the comments by Langleben and Orfanos. Indeed, there has been a controversial discussion on recruitment of perfused vessels, distensibility of perfused vessels and even active vasodilatation of the pulmonary circulation during exercise. Shortly after introduction of right heart catheterisation as a 
diagnostic method, some reports suggested that during exercise, cardiac output may increase considerably with little or no change in pulmonary arterial pressure $[1,2]$. Subsequent studies in healthy adults of different ages and sexes, performed in experienced high-volume centres, could not reproduce these results [3]. Indeed it seemed that the increase in pulmonary arterial pressure was always linearly related to the increase in cardiac output, although the steepness of this relationship was strongly age dependent.

One of the key questions is the amount of pulmonary vascular resistance (PVR) change from rest to exercise. Experimental models using isolated perfused lungs or open chest preparations with positive pressure ventilation found a profound PVR decrease from low to normal pulmonary perfusion pressures [4], but these experimental conditions may not resemble physiological conditions in healthy volunteers. In our literature research of all published data with the use of strict quality criteria, we found no evidence of a strong decrease of PVR during supine exercise, even in young healthy adults $[3,5]$. These results have later been confirmed by others $[6,7]$.

Therefore, we agree with Langleben and Orfanos that it is important to use exact terminology and to carefully analyse the subtle changes in pulmonary haemodynamics during exercise. However, it would be premature to judge the recruitment capacity of the pulmonary vasculature in healthy individuals based on the published literature, or to draw any final conclusions. Much more effort is needed to solve the old physiological questions about the regulation of pulmonary blood flow in humans.

@ERSpublications

It is currently premature to judge the recruitment capacity of the pulmonary vasculature in healthy individuals based on the published literature, or to draw any final conclusions http://ow.ly/BdbP30irkAF

Cite this article as: Olschewski H, Kovacs G, Herve P. Pulmonary capillary recruitment in exercise and pulmonary hypertension. Eur Respir J 2018; 51: 1800260 [https://doi.org/10.1183/13993003.00260-2018].

Horst Olschewski ${ }^{1,2}$, Gabor Kovacs ${ }^{1,2}$ and Philippe Herve ${ }^{3}$

${ }^{1}$ Medical University of Graz, Dept of Internal Medicine, Division of Pulmonology, Graz, Austria. ${ }^{2}$ Ludwig Boltzmann Institute for Lung Vascular Research, Graz, Austria. ${ }^{3}$ Centre Chirugical Marie Lannelongue, Thoracic and Vascular Surgery, Le Plessis-Robinson, France.

Correspondence: Gabor Kovacs, Medical University of Graz, Auenbruggerplatz 20, 8036 Graz, Austria.

E-mail: gabor.kovacs@klinikum-graz.at

Received: Feb 062018 | Accepted: Feb 062018

Conflict of interest: H. Olschewski reports grants from Bayer, Unither Pharmaceuticals, Actelion Pharmaceuticals Ltd, Roche, Boehringer Ingelheim and Pfizer Inc.; personal fees from Gilead Sciences Inc., Encysive Pharmaceuticals Ltd and Nebu-Tec; and personal fees and non-financial support from Bayer, Unither Pharmaceuticals, Actelion Pharmaceuticals Ltd, Pfizer Inc., Eli Lilly, Novartis, Astra Zeneca, Boehringer Ingelheim, Chiesi, Menarini, MSD and GSK, all outside the submitted work. G. Kovacs reports personal fees and non-financial support from Actelion, Bayer, GSK, MSD, Pfizer, AOP, Boehringer Ingelheim, Novartis and Chiesi, outside the submitted work.

\section{References}

1 Hickam JB, Cargill WH. Effect of exercise on cardiac output and pulmonary arterial pressure in normal persons and in patients with cardiovascular disease and pulmonary emphysema. J Clin Invest 1948; 27: 10-23.

2 Riley RL, Himmelstein A, Motley HL, et al. Studies of the pulmonary circulation at rest and during exercise in normal individuals and in patients with chronic pulmonary disease. Am J Physiol 1948; 152: 372-382.

3 Kovacs G, Berghold A, Scheidl S, et al. Pulmonary arterial pressure during rest and exercise in healthy subjects: a systematic review. Eur Respir J 2009; 34: 888-894.

4 Borst HG, McGregor M, Whittenberger JL, et al. Influence of pulmonary arterial and left atrial pressures on pulmonary vascular resistance. Circ Res 1956; 4: 393-399.

5 Kovacs G, Olschewski A, Berghold A, et al. Pulmonary vascular resistances during exercise in normal subjects: a systematic review. Eur Respir J 2012; 39: 319-328.

6 Wolsk E, Bakkestrøm R, Thomsen $\mathrm{JH}$, et al. The influence of age on hemodynamic parameters during rest and exercise in healthy individuals. JACC Heart Fail 2017; 5: 337-346.

7 Argiento P, Vanderpool RR, Mulè M, et al. Exercise stress echocardiography of the pulmonary circulation: limits of normal and sex differences. Chest 2012; 142: 1158-1165. 